\title{
Article
}

\section{There is inconsistency in the effect of empathy training for healthcare professionals and students}

Palmer, Karen, Hill, James Edward and Clegg, Andrew

Available at https://clok.uclan.ac.uk/33844/

Palmer, Karen, Hill, James Edward orcid iconORCID: 0000-0003-1430-6927 and Clegg, Andrew orcid iconORCID: 0000-0001-8938-7819 (2020) There is inconsistency in the effect of empathy training for healthcare professionals and students. Evidence-Based Nursing, 44 . pp. 1-13. ISSN 1367-6539

It is advisable to refer to the publisher's version if you intend to cite from the work. http://dx.doi.org/10.1136/ebnurs-2020-103292

For more information about UCLan's research in this area go to http://www.uclan.ac.uk/researchgroups/ and search for < name of research Group>.

For information about Research generally at UCLan please go to http://www.uclan.ac.uk/research/

All outputs in CLoK are protected by Intellectual Property Rights law, including Copyright law. Copyright, IPR and Moral Rights for the works on this site are retained by the individual authors and/or other copyright owners. Terms and conditions for use of this material are defined in the policies page.

\section{CLoK}

Central Lancashire online Knowledge www.clok.uclan.ac.uk

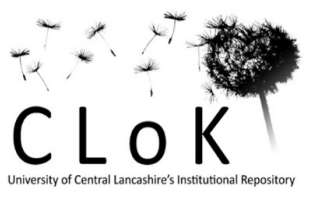




\section{Category:}

\section{Study type:}

Author's declarative title: There is inconsistency in the effect of empathy training for health care professionals and students.

Commentary on: Bas-Sarmiento, P. Fernandez-Gutierrez, M. Baena-Banos. Correro-Bermejo, A. Soler-Martins, P.S. Torre-Moyano, S.D.L. Empathy training in health sciences: A systematic review. Nurse Education in Practice. 2020: 44. 1-13.

\section{Commentary}

- There is inconsistency in the effect of empathy training for health care professionals and students.

- There is a lack of alignment of dimensions of empathy training and outcomes being assessed.

- There is a need for high quality research focusing on important mediating factors for empathy training.

\section{Implications for practice and research}

\section{Context}

The concept of empathy dates back to the 1880s, with the German psychologist Theodore Lipps recognising empathy as the emotional appreciation of another's feelings (1). It is widely acknowledged that empathy plays a vital role in health sciences, eliciting an effective way for health care professionals to understand the experiences of patients without experiencing that state themselves (2). Nurses may develop their empathic skills through lived or shared experiences (experiential learning) or arts methods of humanist learning, such as narratives, poems or role-play (3).

The examination of empathy interventions such as experiential or humanist learning has only been addressed as a secondary outcome in previous literature reviews (3). The authors of this review aimed to address this by reviewing the effectiveness of these training methods in relation to health care professionals' empathic abilities and the maintenance of their skills in practice over time.

\section{Methods}

A restrictive and out of date literature search on six databases from January 2000 to April 2017 was carried out for this review. Only studies of health care professionals and/or students in health science or health professions published in English and Spanish languages were included. Interestingly all types of studies were included apart from descriptive studies. Robust screening and data extraction were carried out by two reviewers, with arbitration by a third reviewer. Three different tools were used to assess the risk of bias, these were the Medical Education 
Research Study Quality Instrument, Guidelines for Conducting and Reporting Mixed Research in the Field of Counselling and Beyond, and Consolidated Criteria for Reporting Qualitative Studies (COREQ). Due to the wide range of research methodologies used in the included studies, qualitative analysis was performed rather than meta-analysis.

\section{Findings}

Nineteen studies were included of mixed design, pre and post-test, quasi-experimental and one qualitative study. Using the range of assessment tools, the studies were judged to be of moderate quality with the main risk of bias being from the use of self-assessment tools for the majority of outcomes.

There were inconsistencies observed in regard to the dimensions of the outcomes being assessed and the focus of the dimensions delivered as part of the intervention, with just over half of the studies $(57.89 \%)$ not assessing the dimension of training. The majority of studies used an experiential training intervention (73.68\%) and the remaining studies used reflexive writing, literature and theatre. There was a notable lack of theoretical framework used within these included studies with only $45.45 \%$ using a theoretical framework of reference.

There was substantial inconsistency in studies demonstrating statistically significant improvement with only $68.43 \%$ of studies demonstrating a statistical significance in an empathy related outcome, with the remaining $31.57 \%$ of studies showing an improvement but not statistical significance.

\section{Commentary}

Using the Joanna Briggs Institute Critical Appraisal tool for systematic reviews 8 out of the 11 criteria were judged to be satisfactory for this review. Thus, it was deemed that this systematic review might provide a comprehensive summary of the available studies that address the question of interest. However, several fundamental issues should be considered when interpreting the results of this review. Firstly, due to the out-of-date search being undertaken this review may be missing relevant up-to-date evidence. Secondly, there were notable inconsistencies in the interventions researched. There was a lack of theoretical framework of reference for the educational sessions and a mismatch of dimensions of empathy which were used in training, and which ones were assessed. This wide variation in intervention type and assessment reduces the confidence that the estimated effect observed in this review represents the true effect. Nevertheless, these findings do highlight some important recommendations for future research.

Future research should ensure that any intervention to improve empathy should be underpinned by a theoretical framework and clearly reported. Due to the substantial inconsistency of effectiveness of empathy training seen within this review, future high-quality research should focus on identifying important mediating factors for empathy training. This research should ensure alignment of the dimension of assessment to the specific dimension of training. As well as these specific dimensions additional patient centered outcomes and qualitative data should be collected enabling triangulation. 


\section{References}

1. Hardee, J.T. An overview of Empathy. The Permanente Journal. 2003: 7(4). 51-54.

2. Halpern, J. What is clinical Empathy? Journal of General Internal Medicine. 2013 18: 670-674.

3. Bas-Sarmiento, P. Fernandez-Gutierrez, M. Baena-Banos. Correro-Bermejo, A. SolerMartins, P.S. Torre-Moyano, S.D.L. Empathy training in health sciences: A systematic review. Nurse Education in Practice. 2020: 44. 1-13.

\section{Commentator details}

Name: James Edward Hill

Affiliation: University of Central Lancashire

Correspondence address:

University of Central Lancashire,

Preston,

Lancashire

PR1 2HE

Email: Jehill1@uclan.ac.uk

\section{Competing interests}

I have no conflicts of interest with any aspect of this publication.

Acknowledgements: This report is independent research funded by the National Institute for Health Research Applied Research Collaboration North West Coast (ARC NWC). The views expressed in this publication are those of the author(s) and not necessarily those of the National Institute for Health Research or the Department of Health and Social Care. 